\title{
ESTADO, TERRITÓRIO E UNIDADE NACIONAL NA REPÚBLICA VELHA.
}

\section{State, territory and national unity in the Old Republic}

João Phelipe Santiago ${ }^{1}$ http://orcid.org/0000-0002-3027-8893

\footnotetext{
${ }^{1}$ Professor titular do Departamento de Geografia da UESB-Bahia-Brasil, email pphhee@ hotmail.com
}

\section{Resumo}

A questão da unidade e da integração nacional é recorrente nas teorizações do pensamento social brasileiro, e perpassa as preocupações dos teóricos do pensamento conservador. A questão nacional no Brasil republicano é central no pensamento de Alberto Torres. Este destaque revela-se através de suas preocupações com as forças que fragmentam e unem a criação de uma unidade nacional. Nesse sentido concebe o desenvolvimento do Estado e do território aliado às questões sociais as questões ambientais, econômicas e culturais. Sobre isso traçamos alguns paralelos com o paradigma ratzeliano.

Palavras-chave: Alberto Torres, Friedrich Ratzel, Brasil.

\begin{abstract}
The question of national unity and integration is recurrent in the theories of Brazilian social thought, and pervades the concerns of conservative thinkers. The national question in republican Brazil is central to Alberto Torres's thinking. This highlight is revealed through their concerns with the forces that fragment and unite the creation of a national unity. In this sense it conceives the development of the State and the territory allied to social issues, environmental, economic and cultural issues. On this we draw some parallels with the Ratzelian paradigm.
\end{abstract}

Keywords: Alberto Torres, Friedrich Ratzel, Brazil

\section{Introdução}

No Brasil o sistema federativo foi outorgado como estratégia política para preservar a unidade nacional. Foi instituído na República Velha, quando foi feito um pacto com as Províncias que foram elevadas à condição de unidades autônomas 
(EGLER; MATTOS, 2003). Esse sistema remonta ao século XVIII resultante de um processo, que culmina com a união territorial do poder das colônias e províncias para formar um Estado. Nesse contexto destacamos o exemplo da formação dos Estados Unidos da América (EUA), como segunda potência territorial das Américas, seguido do Brasil.

O problema da unidade nacional, associado às questões da integração nacional emerge no Brasil Imperial. Paralelamente uma concepção patrimonialista defende o afã de anexação de uma expansão territorial crescente. O governo absolutista legitima esses propósitos, administrando os problemas ligados à população, que ainda tinha um grande percentual ex-escravo, e as economias exportadoras que dificultavam a criação de um expressivo mercado interno; fortalecendo o domínio e gestão do território. Nesse cenário também começa a emergir as questões ligadas à identidade nacional, valorizando a mestiçagem, com significativa relevância no Brasil republicano. A economia-mundo desenvolve suas redes de circulação e comunicação no Brasil, baseada no paradigma da expansão territorial e apropriação de espaços de forma contínua; e centralização do poder político e econômico. O que tornou este país a maior potência territorial da América do Sul, contrariamente ao que aconteceu com o domínio espanhol.

Nesse contexto a Geografia também pode ser entendida como História Territorial (MORAES, 2005, p. 53). Associado a isso desenvolveremos questões recorrentes ligadas aos problemas sociopolíticos da organização e da unidade nacional na República Velha. No foco nessas questões, ressaltaremos o pensamento conservador de (TORRES, 1978 [1914]). Sem deixar de refletir sobre certos nexos de outros expoentes do pensamento conservador da época, que estavam afinados com o pensamento geográfico, tais como: CARVALHO, 1997 [1919], BACKHEUSER, 1926, VIANNA, 1956 [1937], como uma derivação dos estudos de doutoramento defendidos na USP (SANTIAGO, 2005).

Há uma produção significativa sobre a história do pensamento geográfico brasileiro em nexo a formação nacional. Contudo pouco se tem explicitado sobre as contexturas. Esta noção envolve os planos: da evolução geral da geografia; da evolução da geografia nacional; da formação territorial associada aos determinantes: histórico, político, econômico, social e cultural; e para situar o autor ou autores em foco, e a(s) temática(s) produzida(s) em nexo(s) com o(s) contexto(s) histórico/geográfico recortado(s). 
Dessa forma são elaborados os paralelismos lógicos para o entendimento do texto e do contexto de um determinado autor em liame a produção das ideologias de cada época, sociedade, governo. Assim, podemos elaborar uma metodologia genuína que busca uma compreensão da estrutura lógica de cada autor e da temática escolhida na pesquisa como uma determinada contextura. Isso leva a melhor situar seja qual for a temática e a questão fundamental, para mais coerentemente delinear o fio condutor de forma mais objetiva. Também, esta metodologia esclarece sobre a recepção/assimilação do pensamento social brasileiro em um determinado quadro histórico e geográfico, macro determinações, background. Este procedimento pode ser aplicado a um determinado tema ou conjunto temático conexo que reflita a recepção/assimilação de um ou mais autores num determinado lugar, região, território, nação ou época.

Sobretudo quanto ao método na sua essência ontológico, optamos por adotar uma perspectiva mais ampla correlacionada: o método histórico aliado ao método analítico. Sempre contextualizando e conceituando os aspectos lógicos estruturais consubstanciadores dos recortes efetuados para melhor delinear o objeto de estudo como um todo. Nada obstante, o método dialético perpassa toda a argumentação, pois com sua aproximação fundamentamos a crítica aos pressupostos teóricos e epistemológicos embutidos em todo o conteúdo assimilado; compreendendo a filosofia, a geografia e a história como momentos da dialética concreta da realidade, e, por conseguinte da formação territorial.

O pensamento de Torres, selecionado, enfoca questões emergentes na época que tratam da organização do espaço geográfico, da política e da cultura. Fazendo crítica a situação de despreparo e inoperância do Estado frente as verdadeiras questões sociais indicadas, haja vista a herança de um sistema escravista, e que agora tem como meta a afirmação no cenário mundial como um país livre e potência territorial. Já que uma das grandes questões do imperialismo da época, e como se tornar uma potência mundial. Assim, fez sua crítica, procurando observar aspectos que impedem um desenvolvimento mais duradouro e eficiente do próprio Estado.

Diríamos que a estrutura fundamental do paradigma sobre o Estado, território e desenvolvimento contido em Torres, possui paralelo com o pensamento ratzeliano sobre a centralização do estado enquanto organismo preso ao território e solo (Boden), entendido no sentido amplo com recursos naturais, onde habita o povo.

Todavia, é preciso antes de tudo entender os diversos significados que a palavra "Boden" adquire no seu texto. De forma restrita, está diretamente ligada a solo, chão, 
terra, superfície. Não obstante, o sentido mais amplo em certas contexturas pode ser associado à idéia de solo, terra, recursos naturais e território (SANTIAGO, 2005, p. 58; 2013).

Sendo assim, entendemos que existe uma conceituação que faz nexo com todos os aspectos que caracterizam as questões desenvolvidas, na visão de território, sociedade e desenvolvimento. Aspectos que mesclam o pensamento de Torres com o de Ratzel relacionando as ideias de: Estado / território / povo / solo / sentimento nacional nacionalismo / patriotismo / coesão social, formando um bloco orgânico interpretativo.

\section{A organização da sociedade e do território no discurso de Alberto Torres}

A formulação de propostas para resolver $o$ problema nacional é uma constante neste campo temático que escolhemos. O Brasil estava na aurora de se tornar uma nação reconhecida mundialmente. Mas tinha uma grande base territorial, um povo pouco escolarizado, uma herança de homens livres ex-escravos, problemas regionais como a seca, e um território para ser povoado, ou seja, a rede de circulação e comunicação era ainda incipiente, e o país um grande arquipélago desintegrado economicamente.

O discurso de Torres busca as causas que entravam o desenvolvimento da nação e da sociedade, situando para isso aspectos de análise territorial, envolvendo a política, a psicologia social, a questão ambiental e as qualidades da natureza.

“O nosso país precisa de uma vez por todas, formar um espírito e uma diretriz que o conduza, salvando-o do atravancamento das opiniões e das tendências particularistas e sistemáticas, em que está dividido, a organizar e por em movimento as suas próprias forças”. Assim, para Torres (1978, p.19-21) seria imprescindível o país se organizar a partir do movimento interno. Já que haveria causas históricas e políticas da desorganização nacional que seriam de três ordens. A primeira estaria ligada à grande perda de energia que usou o colonizar, em ter que defender o território resultando num "improfícuo esforço defensivo". A Segunda seria resultado da "disparidade da terra colonizada com a dos colonizadores, apresentando problemas de adaptação e de cultura, até agora não resolvidos" e a terceira seria ligada à "síncope da evolução política, com a vinda da casa de Bragança".

A essas causas acrescentou que existiriam outras de "natureza social e política". Os fatores naturais aparecem associados à questão ambiental e ecológica, incluindo 
denúncias sobre a "política colonial". O que nos fez acreditar que ele seja um dos precursores dessas preocupações ecológicas e geopolíticas em liame à questão nacional. Sua perspectiva de análise da relação homem-meio não possui, claramente, o ingrediente fatalista. Como em Backheuser (1926), aspecto de sua visão não somente em relação à natureza, como em relação à caracterização do caráter nacional do povo brasileiro.

No Brasil, o ressecamento das terras e do ar, as secas periódicas, cada vez mais prolongadas [...] fato ordinário em vastíssimas regiões do território, e já patente em outras onde foram outrora abundantes as águas [...] na quase esterilização das nossas pastagens e falta de forragens, durante longo período do ano, fruto principal das nossas devastações e da política colonial que temos feito [questão que também atinge as] populações das grandes cidades, com as crises da 'falta de água' de ano para ano mais penosas (TORRES, 1978, p.1921).

Torres dizia acreditar que a exploração das riquezas naturais deveria corresponder aos "interesses políticos da nossa nacionalidade". Entendia que a "metalurgia, que levaria a consolidação da economia nacional". Sobre as riquezas preciosas do "nosso solo", disse que é preciso salvaguardar a terra das "audaciosas devastações", preservar as matas virgens e "restabelecer as que já estão comprometidas". Igualmente, sugeriu uma espécie de desenvolvimento racional, que deduzimos teria haver hoje com o manejo e gestão da complexidade natural, nos levando a pensar como um contraponto sobre o que hoje teria um significado como desenvolvimento sustentável.

Entre as leituras efetuadas consideramos a perspectiva de Torres como um autêntico anunciar da crise da natureza e do trabalho no Brasil ${ }^{2}$. Por isso, consideramos sua obra sobre a questão nacional de uma atualidade significativa.

A influência do paradigma darwiniano e ratzeliano reaparecem em Torres (1978, p.22) quando falou da gravidade dos problemas nacionais, e se referiu à tríade [Pátria nação = gente (povo)], e à necessidade da defesa pelo povo contra "qualquer inimigo". Entretanto, colocou a idéia de população (povo) para explicar as diferenças de classe, numa situação de subordinação que chamou de "processos da seleção social e econômica"; reafirmando que "o nosso problema vital é o problema da nossa organização". Acreditando que era dever de sua geração lutar pelo crescimento e

2 Sobre esta questão consultar o trabalho de Alberto Torres As fontes da vida no Brasil (1915).

V.1, n. 1, 2017 http://periodicos2.uesb.br/index.php/geo 
progresso do país, ao mesmo tempo em que demonstrou estar desiludido com a corrupção governamental.

O Estado é, no Brasil, um fator de dissolução. A influência deletéria dos interesses anti-sociais, criados e alimentados em torno do poder público, desde os municípios até a União, sobre a vida brasileira, é um fato cujo alcance não foi ainda atingido pelos observadores das nossas coisas públicas. Este regime deve ser substituído por outro, capaz de levar a termo o encargo da geração presente para como futuro do Brasil (TORRES, 1978, p.23).

Refletindo sobre esta passagem podemos pensar que as suas propostas estavam voltadas para o fortalecimento do Estado. Sugerindo formas de organização nacional aristocrática/autoritária de viés populista, através do desenvolvimento de um "espírito" superior para as elites e uma educação básica para o povo. Por outro lado, a sua interpretação ligada à ideologia de um nacionalismo patriótico confirma não só através dos elementos de sua análise, um diagnóstico que indica um Estado com problemas de unificação devido a carência de suas "elites” (Torres) de uma visão "superior” (Ratzel) do próprio país, visto que são inúmeros os sintomas de instabilidade social e fragmentação política identificados. Nesse sentido, percebemos que as alternativas colocadas convergem para uma solução que entra em consonância com a visão ratzeliana do Estado.

\section{Paralelos com a visão ratzeliana de Estado}

A perspectiva religiosa e idealista aparece desde o início da análise sobre "senso, consciência e caráter nacional" contida na obra O Problema Nacional Brasileiro de Alberto Torres (1978 p.24-5). O nacionalismo já aprece na primeira frase: "Não terás deuses estrangeiros diante de mim". A idéia de espaço vital, no que se poderia deduzir da noção de Lebensraum de Ratzel (SANTIAGO, 2005, p. 80, 97, 166), situa-se quando se referiu à criação da vida racional falando da tríade "Deus, o espaço e a grei confundiam-se nos espíritos Estirpe e bando: a sociedade de interesse vital, em gestação". Embora seja uma alegoria e imagem mítica, essa noção vai aparecer em outro contexto de sua exposição; igualmente a expressão "interesse vital", é encontrada 
nas formulações ratzelianas sobre o desenvolvimento do Estado-nação e a questão nacional ligada às razões de proteção, coesão interna e a unidade nacional.

Da mesma forma, a idéia de sentimento nacional na abordagem de Torres está ligada a idéia de "espírito da nação" e ao sentido coletivo de proteção. O laço de união se expressa assim num complexo que envolve: raça, língua, território, lenda, religião, nação e identidade. Analogamente, a noção de nação também pode ser equacionada relacionando-se País/raça, Pátria/língua, Estado/religião. Ademais, esta idéia também está ligada na exposição dele ao liberalismo e a própria nacionalidade étnica.

Para o autor a "nação brasileira, primeiramente é a associação dos indivíduos" e famílias que habitam o Brasil com ânimo de permanência, protegidos pelo conjunto dos órgãos de sua política: o Estado; formando, sobre seu habitat territorial: o 'País' [...] uma 'Pátria'". Tudo isso, lembra o sentido primário que Ratzel atribuiu à formação inicial do Estado. Este com a missão central de proteger o território, noção que se amplia com o sentimento nacional e o nacionalismo. Dessa forma, Torres converge para o raciocínio ratzeliano; em outras palavras podemos estabelecer um paralelismo por ele ter falado no sentido do papel do Estado e da identidade que o povo cria com o sentimento patriótico de "laço de proteção [...] de assistência", pois, em Ratzel está clara a função protetora do Estado, para salvaguardar os interesses internos vitais à sua estabilidade e seu crescimento. Igualmente, o autor demonstrou seguir outro raciocínio ratzeliano quando falou de solo/terra, como "base da vida social" e junto a isso o "desenvolvimento [do] sentimento nacional"; o solo/terra, como "patrimônio material da nação - berço da sua existência, sede da sua ação, recinto da sua vida, paisagem de suas dores e de suas alegrias". Referindo-se também ao "patriotismo territorial", definindo-o como "sentimento real" entre as pessoas; levando assim, a uma outra idéia que associa um sentido de comunhão formando o "senso nacional", que seria diferente segundo o próprio povo variando historicamente. Ratzel fez um raciocínio semelhante associando a idéia de terra natal (heimat) / patriotismo/nacionalismo/senso nacional/coesão social.

Por conseguinte, deduzimos que tais noções e argumentos possuem um paralelo evidente com o ideário ratzeliano, porque Estado/território/povo/solo/sentimento nacional, formam um bloco orgânico interpretativo, cuja consciência nacional, quanto maior for mais forte será o Estado e seu povo. Havendo também uma semelhança com o conceito de "senso geográfico" que Ratzel também indica que varia historicamente e de acordo com o povo. 
De outra forma, também podemos fazer um paralelo com as idéias de Ratzel já apontadas anteriormente, quando ele se refere ao nacionalismo e ao senso nacional [Nationalsinn]. Tal conceituação estaria ligada primeiramente ao "sentimento do laço ao solo", que seria mais forte onde "o solo é bem delimitado, que nós podemos o abraçar numa piscadela, que é mais fácil de dominar e de explorar, principalmente então nas ilhas onde a força do nacionalismo dos habitantes exprime-se numa consciência maior do solo" (RATZEL, 1987, p.60-2).

Sobre a relação: raça e nacionalidade, Torres (1978, p.28-31) disse que ela é o elemento "talvez menos ativo" da nacionalidade. Seguindo a mesma influência ratzeliana de que nenhum povo atualmente é formado de uma raça homogênea, questão que Ratzel chamou de povos de "tipo misto". Torres disse acreditar que o número de "raças puras é limitadíssimo"; posicionando-se contra o preconceito aos latinos, que seria etnicamente negativo para o desenvolvimento cultural, rebatendo com argumentos que mostram uma correlação da "identidade de temperamento e simpatia [...] que entra no espírito nacional". Ainda lembrou a importância de ser cosmopolita no sentido de aprender com os povos de outras nacionalidades; entretanto, advertiu contra o abuso que a idéia de raça é adotada no Brasil, mostrando que não está correta a generalização de idéias sobre a capacidade específicas das várias raças e a falta de discernimento sobre as razões das características étnicas, evidenciando que o processo da "evolução nacional e política realçaram, por força dos costumes e das instituições, os fatores puramente sociais de seleção".

A idéia que nos cumpre assentar e consolidar no espírito, em lugar da noção inconsciente e pueril em voga, é a desta profunda e grave sentença de Ratzel: 'A diferença de civilização, entre dois grupos da humanidade, não tem relação com a diferença de seus dotes' [RATZEL - The history of mankind].

O fator social foi considerado a influência mais marcante em relação aos fatores étnicos e mesológicos, pois, o "homem moderno" é o resultado do meio onde habita e "principalmente da sociedade que o cerca", o indígena de outrora "selvagem e antropófago" como o "preto", hoje, apresentam-se, como cristãos e moralizados, civilizados. Falou da necessidade de um "afeto patriótico", como igualdade e cordialidade em relação aos estrangeiros que formam a nação. Disse: "temos que reconhecer senão homens, senão semelhantes, seres da mesma natureza e do mesmo espírito". Criticou a escravidão como uma instituição amaldiçoada, e a República como 
"sendo um jogo floral de teorias, sobre um campo de misérrimas realidades". Atribuiu ao trabalho do negro e a labuta do senhor, o resultado da edificação do país, da "estabilidade social e dinamismo orgânico progressivo".

Perplexo com a descrição que fez das fronteiras do conhecimento da época, Torres (1978, p.36-41) buscou entender a complexidade da realidade que lhe fugia, cuja dimensão mais abstrata é o limite das suas explicações querendo entender o "assombroso fenômeno complexo do espírito humano". O homem na sua definição influenciado pela antropogeografia é um "ser em quem o fenômeno da vida reuniu as condições e propriedades mais complexas da 'adaptatividade"'. Dessa forma, observamos que o autor nos seus vários argumentos e descrições sempre retorna para aspectos substantivos do paradigma ratzeliano, sobretudo, na perspectiva lógica de uma visão do mundo teleológica que busca a causalidade e relatividade de toda a realidade. Embora procure separar a dimensão divina das causas humanas, seu raciocínio global tende a mistificar a luta de classes e a hegemonia estratégica interna dos grupos de poder, pintando assim de neutralidade axiológica sua perspectiva autoritária, mesclada pelas críticas sagazes construtivas da ordem e do poder existente.

Nas suas argumentações há sempre um encadeamento lógico que vai se substanciando com os pressupostos ratzelianos; refletindo a imagem de um Estado autoritário paternalista. Religião, política e polícia estariam juntos para justificar a segurança e os destinos da nação, que evoluiu desde as formas rudimentares, as monarquias e a criação das sociedades modernas, modelando uma visão que quer admitir uma correspondência um tanto linear entre o indivíduo e a nação, raciocinando como se a riqueza da nação fosse simplesmente a riqueza dos indivíduos e vice-versa. Lembra muito o critério da média como válido para diagnosticar, como seria a densidade populacional ou a renda per capita; o que evidentemente, é um raciocínio que esconde mais do que revela a realidade como ela realmente é.

Sobre os interesses dos dominadores e a evolução histórica do Estado se complexificando em sua estrutura jurídica, Torres disse que acreditava no contínuo e ascendente "progresso moral" e na "prosperidade material" das populações, vistas como "grandes massas da sociedade". Dessa forma, semelhante à Ratzel, Alberto Torres concebeu o Estado como centralizador e soberano para resolver os problemas coletivos e futuros, como árbitro da responsabilidade do homem; legitimando igualmente a forma coercitiva das leis, a quem o homem civilizado está condicionado, ou seja, a própria coibição exercida constitucionalmente pela força. $\mathrm{Na}$ "relatividade da sua vida objetiva, 
ficaram entregues à única força e única autoridade efetiva e prática sobre seu arbítrio e sobre sua responsabilidade: o Estado, órgão da nação". Ao mesmo tempo, o autor trabalha a idéia de "massas humanas" levando em conta a sua interação com o mundo físico considerando os efeitos sobre sua vida psíquica; habitat e sociedade; "meio, povo e forma política" observados como um corpo, logo um organismo.

Dessa forma, há também um paralelo com a concepção ratzeliana de população como massas em movimento e ainda com a perspectiva "hologeica" de sua Antropogeografia, que intentou apreender o universo enquanto movimento harmônico entre as partes e as esferas constituintes. Além disso, Torres nos convida a pensar do observatório ratzeliano, que como demonstramos, aprofundou o princípio de reciprocidade, situando os movimentos populacionais, como movimentos de massas importantes na vastidão do "teatro" da história (RATZEL, 1990 a, p.41).

Entendemos que a realidade representada por Torres (1978, p.42-4) é um todo harmônico e sem contradições, como se a totalidade fosse a soma aritmética das partes. Num raciocínio de justaposição, redutível a dicotomias cujos fatores ou elementos se influenciam reciprocamente, deste modo, o progresso seria resultado da relação recíproca entre os indivíduos e a sociedade. Surgindo as nações, as diversas crises, e os efeitos do desenvolvimento através dos instrumentos mercantis se produziram desproporções e perturbações na evolução da manipulação do poder "sobre os destinos das classes inferiores”. Assim, haveria um desconhecimento do problema nacional, não só pelas classes inferiores, como pelos herdeiros das grandes fortunas, pois, como afirmou: "cada indivíduo desconhece o problema da formação estrutural do seu organismo". A questão da colonização é interpretada mais como uma invasão e conquista, como uma mera exploração, onde não estaria em curso a formação de uma nação, mas como disse uma espécie de "mutação gigantesca".

Outras nuances do pensamento ratzeliano podem ser identificadas quando Torres falou sobre as nações novas e tentou explicar as características do Brasil. Embora, adaptando a um pensamento que se pretende crítico sobre a tomada de consciência da situação de atraso e dependência devido à estrutura econômica exploradora e exportadora. Ressaltando ainda, a morosidade com que acontecem as transformações que seriam necessárias para que a sociedade viesse realmente a se constituir, pois, estava imersa nos interesses que provocam a desintegração social. Nesse sentido, disse que no Brasil os elementos - língua, religião, raça - que promoveriam a coesão social 
aqui são "dissolventes". Temos, portanto a missão de "construir artificialmente a nacionalidade" como "corpo estrutural da sociedade política".

Comparando os Estados Unidos da América com o que pressupõe sobre uma "positiva psicologia social”, refletiu que mesmo não sendo uma "nação", propriamente, revelava uma maior "vitalidade" e maiores "requisitos de evolução organizadora". Contrariamente, no Brasil seria necessário construir esses requisitos para uma organização nacional eficiente, que não seria simplesmente, "uma Constituição e umas centenas de leis, empalhadas em volumes, não fazem um Direito; quanto mais, a vida de uma nação!"”.

No pensamento de Torres (1978, p.47) a nacionalidade brasileira está ligada ao povo e a sua vida, ao espírito e a sua energia, a sua saúde e economia da Pátria, ao espírito das suas raças, a sua natureza tropical, ao seu patrimônio territorial. Dessas relações, levantou a necessidade de se traçar uma política formadora da "consciência nacional", pois, sem essa consciência não poderia haver "autonomia de um povo".

Paralelamente, defendeu uma visão patronal e patrimonial, propondo como questão de segurança e de patrocínio a centralização em torno do chefe e do governo. Estrategicamente Torres (1978, p.50) explicou que se trata de "um estado de consciência e um impulso de instinto: o chamado espírito nacional dos povos" contra o inimigo externo. Uma "forma superior de nação" deve ter como ideal de "progresso" o que "o espírito envolve, na síntese mais ampla, os móveis íntimos da solidariedade social, fazendo-a reverter para o futuro, para o interesse da prole". A "vida nacional" é mais que a soma das partes individuais em atividades, do que acontece socialmente no território, é uma "vitalidade especial"; que produz "fenômenos de desenvolvimento, de prosperidade, de progresso, de civilização e cultura, de indivíduos, famílias, classes e associações [produzindo] um complexo de forças e de valores, que progridem em nível ascensional, de alcance, e em linha horizontal, no tempo, para o ideal adaptativo".

\section{O destino nacional}

Assim, concebeu o destino da civilização na construção paulatina de um equilíbrio e uma harmonia entre os homens, e destes com a terra ao sabor das gerações se conservando, culturalmente e materialmente; como disse, na contenção do “desenvolvimento da riqueza e da energia, a civilização cria, sobre a rusticidade da terra 
e sobre a imperfeição humana, o ambiente que acumula e que impulsiona os progressos". Percebe-se assim, a identificação que tem o autor com as noções ratzelianas de desenvolvimento cultural e material concebidas historicamente e cumulativamente. Além de refletir num sentido que imaginou a existência de uma visão de espaço que não limita as partes em si mesmas.

Torres $(1978$, p.53) diferenciou o desenvolvimento do progresso material dos indivíduos e classes, achando que o movimento em si da "massa de indivíduos e a de seus agrupamentos não é o elemento dinâmico da vida nacional: é o seu elemento estático; não é a sua força progressiva; pode ser-lhe uma força retrocessiva. É este literalmente, o caso da nossa Pátria”. Seria necessário, segundo o autor produzir indivíduos lhes coordenado à direção política e cultural. "Não é um problema de moralidade pessoal [...] o problema da nossa vida não é o problema do caráter individual, é o problema do caráter nacional".

Um dos aspectos essenciais que o autor passou sobre a idéia de caráter nacional nos fez refletir sobre o que considerou como a imaturidade da emergente nação brasileira ainda presa a cultura importada europeia e norte-americana; mas que, por outro lado, lutava para produzir seus próprios caminhos, suas próprias "sementes", sem abandonar os "frutos do nosso clima". Dessa maneira leva o leitor a crer que o genuíno sentimento nacional seria um sentimento "consciente e sincero", o que para nós se trata de uma idéia que tem o qualitativo significativo vago; embora o fato apontado com relação ao desperdício em relação a uma atitude mais racional, de conhecimento da relação natureza do território e a economia esteja correta dentro do que hoje se chama desenvolvimento sustentável.

O ecletismo de Alberto Torres e o excesso de eloquência do seu estilo, coisa comum na época criou uma mesclagem ideológica que parece desejar cativar o leitor quanto às denúncias sobre as irracionalidades e os absurdos consequentes da formação social brasileira. Não acreditava que as reformas fundamentais se resumissem com as construções e edificações de estabelecimentos econômicos e públicos. Para Torres (1978, p.54) as "reformas" começam com a "mudança de atitudes", não bastando considerar "dois, vinte ou cinquenta aspectos da nossa vida social e política; é mister abranger, na complexidade dos interesses do povo". Entretanto, sua idéia sobre o caráter nacional e a questão nacional o levou para numa classificação vaga de valores morais e psicológicos tais como: candura da alma, amor à paz, tolerância, grande capacidade de trabalho, chegando a pensar com uma dose de ironia que o destino do povo, logo da 
nação estaria nessa sorte psicológica e moral, no caráter coletivo. Por isso, classificamos as suposições finais do autor como caindo no vazio - da crítica irônica destes limites psicológicos e morais - a que chegou sua visão de mundo elitista e heroica, que se vê presa nas suas próprias metáforas. Bem que, de razoável lembrança de certas passagens de Nietzsche que estava em busca de uma moral de um super-homem, contra os valores burgueses decadentes.

Mais isso não pode ser tão evidenciado, pois, o autor estava sempre envolto com os estigmas de uma ideológica autoritária, que embora se certificasse dos progressos do conhecimento científico, e da necessidade de reformar o mundo buscando acabar com as distorções que geram as desigualdades; o cerne de sua lógica política e ideologia geográfica assentam-se na Antropogeografia e na Geografia Política de Ratzel, colocando o Estado acima da Sociedade, compactuando com uma resolução dos problemas ao nível institucional de cima para baixo, a favor das classes dominantes burguesas, e da forte centralização do poder estatal; pois, uma das questões que fundamentava o destino do povo estava atribuída a sua própria força de caráter diante das adversidades a enfrentar e resolver.

Nada obstante, o autor não faz a crítica da relatividade dos seus pressupostos éticos e políticos, pois sendo a formação sócioespacial do país (como Milton santos nos ensinou) fruto da interação entre o poder estatal, a sociedade, e o usufruto do território, como quer provar, caso não dê certo, busca-se uma explicação a partir do caráter. Sendo assim, na nossa interpretação seria necessário desmistificar antes de tudo a essência do jogo de interesses que move ao longo da história nacional a própria formação do Estado concebido miticamente, e a manipulação da população compreendida como um fator geográfico; mas que concretamente possui o significado - conforme uma Geografia de Estado - de classe dominada a serviço da hegemonia política e econômica que produz sua própria reificação.

Por conseguinte, podemos afirmar que a explanação de Alberto Torres na forma essencial e concreta como se apresenta foi ideologicamente cooptada por uma ideologia geográfica que remonta ao que Moraes (1989) chama de contexto prussiano, e que sendo adaptada ao capitalismo na sua emergência tardia no processo de unificação e consolidação da federação brasileira assumiu um caráter camuflado; embora se vestindo de uma linguagem científica moderna, e colocando a sociedade numa certa situação de urgência em relação a soluções políticas, econômicas e culturais. 
Por tudo isso inferimos que seu pensamento estabeleceu filiações às ciências sociais, e também à geografia moderna tendo em Ratzel um interlocutor de destaque na época, que embora admitisse a multiplicidade das determinações e a complexidade da análise do todo, caiu no reforço de soluções estruturais para gerir a centralização do próprio Estado. Reconhecendo a importância social, mas, que estrategicamente se perde taticamente no amparo à subjetividade da crítica à alienação da própria sociedade civil, tida então como povo, coletividade, massa, como mero fator geográfico ainda não suficientemente organizado.

Neste patamar da discussão, aduzimos que os ideólogos autoritários se valeram de prerrogativas semelhantes quanto à adaptação de pressupostos científicos e ideológicos que servissem para justificar um Estado forte, centralizado e que fosse aberto a certas inovações da nova divisão internacional do trabalho que a moderna sociedade industrial reclamava. Já que, as modernizações tardias que aqui se processavam estavam atreladas às exigências do modelo financeiro internacional. Mesmo que fossem diferentes as visões de mundo e da sociedade, eram a favor da difusão da educação básica e necessária ao desenvolvimento capitalista, no que não ingressasse diretamente em choque com os valores éticos e políticos hegemônicos.

\section{Considerações finais}

Embora não tenhamos desenvolvido as características da organização territorial dessa época, pois objetivamos destacar os nexos interpretativos da visão política e social de Torres, é importante ressaltar alguns aspectos que remetem para a visão de Estado e território e algumas características do Brasil moderno que estava sendo construído.

As conclusões deste artigo derivam de uma pesquisa maior sobre a questão nacional na geografia ratzeliana e sua assimilação no pensamento brasileiro na República Velha, que foi extraído do discurso ratzeliano diluído nas suas obras Antropogeografia (Anthropogeographie), Raças Humanas (Las razas humanas Völkerkunde), Geografia Política (Politische Geographie) e algumas referências do Kleine Schiften, essenciais para entendermos a sua concepção da Geografia - ciência moderna aplicada a uma Geografia do Estado, particularizada na emergência da unificação alemã e no problema da integração e da unidade nacional brasileira. Outras conexões foram aduzidas de vários estudos que fazem referência à geografia ratzeliana na sua perspectiva hologeica. Igualmente, estão difusas em sua obra outras postulações 
importantes, as quais reforçaram a percepção de que a sua teorização geográfica é muito mais ampla e complexa do que os reducionismos imputados a ele e à Escola Alemã em oposição à Escola Francesa. Mas que não se pode aprofundar neste texto.

Na questão nacional e no problema da unidade nacional na República Velha, existem argumentos e elementos conceituais recorrentes às leituras e à assimilação do pensamento de Ratzel. A identidade desses pensamentos assim adaptados consubstanciou o juízo legitimador do Estado pela via do sincretismo cientificista, destacando-se uma lógica positivista. Isso nos leva a afirmar que há um conjunto onde existem vários aspectos que reforçam a tese que demonstramos por linhas gerais da teorização dos autores brasileiros que associaram nas suas idéias uma política territorial inevitável do Estado-nação, na busca permanente do equilíbrio interno necessário ao fortalecimento da unidade territorial e administrativa, centralizada, essencial para a afirmação do país em face das potências mundiais. Este conjunto de conexões, que, em suma, integra o significado e o sentido da noção de coesão perpassa as temáticas desenvolvidas por Alberto Torres, Elysio de Carvalho, Oliveira Vianna e Everaldo Backheuser. Eles se embeberam de vários aspectos da teorização ratzeliana acerca do Estado e da concepção de ciência geográfica, ainda se utilizando, enquanto instrumento teórico, da análise de vários aspectos sobre a cultura, metamorfoseada na produção de uma ideologia a favor do fortalecimento do Estado-nação e dos grupos de poder que administraram e fizeram o governo. Por vias legais e autoritárias, justificaram política e cientificamente a exclusão do povo das decisões centrais estatais, tendo sua participação situada hierárquica e abstratamente diluída na noção de população, quando o mais concreto se refere à divisão social do trabalho. Embora neste recorte aqui apresentado tenhamos dado ênfase aos aspectos observados mais por Alberto Torres.

Esses autores alertaram sobre as forças contra a unidade nacional, como perigosas e geradoras de fragmentação da centralização do poder estatal, ou seja, as razões significativas que comandaram as diretrizes dos discursos em prol do projeto unificador e autoritário do emergente Estado-nação brasileiro, que se consolidaria no período pós-30, obtendo notoriedade com a era Vargas.

Com relação às idéias sobre os interesses expansionistas do Estado-nação e a política de articulação interna, observamos que os planos da necessidade de uma integração nacional remontam ao período histórico anterior. Tais questões estão contidas no problema da fraca circulação do território, cujas respostas foram sendo dadas com a criação do correio, da navegação de cabotagem, do cabo submarino e de 
outras infraestruturas, como os telégrafos, as ferrovias e as estradas com o advento do transporte rodoviário, além de outros inventos ligados ao desenvolvimento da mecânica e, posteriormente, da energia elétrica, que contribuíram com a edificação do Brasil moderno. Tal processo ganhou novos impulsos com o desenvolvimento de novas tecnologias à medida que iam sendo incorporadas à vida urbana, como a edificação da sociedade industrial e a expansão das plantations agrícolas exportadoras como é o caso da cafeicultura que se espalhou do Vale do Paraíba ao oeste paulista, gerando uma forte polarização convergente a São Paulo e Rio de Janeiro, em detrimento da crise do açúcar no Nordeste.

\section{Referências}

BACKHEUSER, Everardo. A Estrutura Politica do Brasil. I - Notas Prévias. Rio de Janeiro. Mendonça. Machado e Cia. Editores. 1926.

CARVALHO, E. A realidade brasileira (1922). In: Obras de Elysio de Carvalho: Ensaios. Brasília. Universa - UCB, 1997. p.199-222.

CARVALHO, E. O Fator Geográfico na Política Brasileira (1921). In: Obras de Elysio de Carvalho: Ensaios. Brasília. Universa - UCB, 1997. p.193-196.

CARVALHO, Elysio de. Brasil, Potência Mundial (1919). In: Elysio de Carvalho: Ensaios. Brasília. Universa - UCB, 1997. p.187-189.

EGLER, Cláudio e MATTOS, Margarida. Federalismo e Gestão do Território: as Regiões Integradas de Desenvolvimento. In: Anais do V Encontro Nacional da ANPEGE, Florianópolis-SC, 2033 (426-434).

MORAES, Antonio C. R. de. Território e História no Brasil.2.ed. São Paulo. Annablume, 2005.

RATZEL, Friedrich. Politische Geographie. 1 ed. Leipzig, 1897. München und Berlin, 1923. Druck und Verlag von R. Oldenboug. Otto Zeller Verlag. Osnabrück, 1974.

RATZEL. F. "As Leis do crescimento espacial dos Estados”. In: MORAES, Antonio Carlos Robert. (Org.). Ratzel. São Paulo: Ática, 1990, p.175-192.

RATZEL. F. “As Raças Humanas”. In: MORAES, Antonio Carlos Robert. (Org.). Ratzel. São Paulo: Ática, 1990, p.108-150.

RATZEL. F. “Geografia do Homem”. (Antropogeografia). In: MORAES, Antonio Carlos Robert. (Org.). Ratzel. São Paulo: Ática, 1990, p.32-107. 
RATZEL. F. "O Solo, a Sociedade e o Estado". In: revista do departamento de GEOGRAFIA 2. São Paulo: USP/FFLCH. 1983, p.93-109.

RATZEL. F. La Géographie Politique: Les concepts fondamentaux. Libraire Arthème Fayard. 1987.

SANTIAGO, João Phelipe. A questão nacional na geografia ratzeliana e sua assimilação no pensamento social brasileiro na república velha. Tese de Doutorado. Universidade de São Paulo. São Paulo: USP, 2005.

SANTIAGO, João Phelipe. Espaço Geográfico e Geografia do Estado em Friedrich Ratzel. Vitória da Conquista. Edições UESB. 2013.

SANTOS, Milton. Por uma Geografia Nova. São Paulo. Hucitec/ Edusp. 1978.

TORRES, Alberto. As fontes da vida no Brasil. Imprensa nacional. 1914.

VIANNA, O. Populações Meridionais do Brasil: História - Organização Psycologia. Populações Ruraes do Centro-Sul: paulistas - Fluminenses - Mineiros. Vol. 1. São Paulo: Companhia Editora Nacional. 3e. 1933 [1918].

VIANNA, Oliveira. Evolução do Povo Brasileiro. Rio de Janeiro: Livraria José Olympio. 4 ed. 1956 (1937).

WALLERSTEIN, Immanuel. El moderno Sistema Mundial. V. I. México: Siglo XXI, 1987.

Recebido em: 20/09/2017

Aceito para publicação em: 11/10/2017 